\title{
alphauille
}

\section{Dysfunctionalities. Annual Conference of the German Society for Media Science (GfM) Potsdam, Germany, 58 October 2011}

A Conference Report by Patricia Prieto Blanco, Huston School of Film and Digital Media, National University of Ireland, Galway

During the 1970s the intense use of audiovisual media in Germany encouraged a vigorous debate among philologists. The outcome of this discussion was the establishment of Media Studies as an independent discipline in the German high education system in the second half of the 1980s ("Fachgeschichte"). The German Society for Media Studies was founded in November 1985 as a forum for academic exchange and dialogue, as well as an initiator of public debate around media-related issues. Aesthetic, historical, sociological, psychological and communicational perspectives were equally considered within the GfM, and this multilayered critique of media production and consumption continues today ("Der Gesellschaft"). Once a year, members of the GfM and visiting academics meet to discuss current theoretical and methodological topics of the discipline under a broad thematic umbrella, which is usually summarised using a single word. The annual conference also serves as a platform for fresh theoretical perspectives, by introducing academic newcomers and their ideas to established Media Studies theorists.

The programme of the GfM 2011, with over forty panels, reflected the productive variety of viewpoints within this academic discipline as well as the increasing interdisciplinary work between Media Studies and other social sciences, such as Film and Gender Studies, Philosophy and Computing. The motto of the conference was "Dysfunctionalities", an idea reflected not only in the topics of the conference, but also in its very structure. While usually running for three days in one fixed location, "Dysfunctionalities" was extended to a fourth day and took place in venues scattered across the city of Potsdam. The benefits of this restructuring were obvious: the extra day was dedicated to a rich and diverse programme, focusing on the pulse of the current state of Media Studies in Germany, while the proximity of the various venues, when coupled with the rather small size of Potsdam, gave participants the opportunity to stretch their legs between events and enjoy the magic of the centenary anniversary of the Studio Babelsberg on the way. 


\section{A Place for Everything and Everything in its Place}

The conference opened at the Technical College Potsdam with an interesting keynote by theorist Rick Altman on the motto of the hour: "New Wine in Old Wineskins: The Many Functions of Media Dysfunctionality". His core interests and influential theory work on film sound and film genre, particularly Hollywood musicals, played a role in his dynamic (some even described it as funny) introduction. The distinctiveness of this first keynote was to offer a first approach towards the concept of dysfunctionality and its potential for productivity within Media Studies. These two points were frequently revisited by panellists and audiences during the following three days.

In the call for papers "dysfunctionality" was described as a term encompassing "everything that doesn't work or that doesn't work anymore, everything that undermines given functions or that resists those" ("Jahrestagung 2011"). In accordance with this definition, the titles of the panels featured keywords such as "disintegration", "interferences", "ambivalence", "accident" and "error" (e.g. "I am Error: Interferences and Dysfunctionalities in Computer Games", or "News and Noise: Towards Cases of Interferences of New Media"). These topics were themselves linked to single media such as cinema or photography; to more general concepts like memory or aesthetics; to specific issues of a medium, like film narration or amateur photography; and to interdisciplinary approaches such as media culture and education or experimental cinema and gender. At least five panels on different themes ran simultaneously so that all participants could find something of interest to attend. The titles of the panels functioned as slogans rather than rigid definitions of their content; therefore the collection of abstracts provided at the time of registration was the best guide for navigating the conference. Sometimes the typography itself revealed the theme of the panel (e.g. "DES ORIENTIERUNGssinns" or translated "Senses of DIS ORIENTATION"). At other times the content of a discussion (e.g. "Media of Pollution") could only be speculated upon by the descriptive framework of the panel ("Dysfunctionality as a Category of Politics: Discussion of New Forms of Control and Knowledge in Relation to their Integral Dysfunctional Character").

The keynote speech by Candice Breitz, entitled "An Artist's Perspective", closed the second day on a high note. Her video installations confront viewers with critical readings of icons of popular culture and subvert traditional methods of visual storytelling, offering for instance a counter-position to the idea of the portraiture genre in Inner+Outer Space or dislocating famous actors and actresses from their various incarnations in Him+Her. As for the keynote, Breitz's vision of media production, through an effective approach towards difference, highlighted the relevance of creative thinking when dealing with concepts such as disorder, dislocation and/or dysfunctionality.

The annual conference provided members of the Society's working groups with the opportunity of meeting face-to-face to evaluate the work of the past twelve months, as well as to plan the year ahead. Later, in the general meeting of the GfM, all working groups shared their plans in the plenum, thereby actively contributing to the overall progress of the Society. The slot reserved for the meeting of the working groups in Potsdam was especially convenient. Placed 
between the coffee and lunch breaks, it afforded groups the opportunity to extend their formal debates in a more relaxed atmosphere.

"Misguided repetitions" was the leitmotiv of a highly interesting panel on remediation and film. Bianca Westermann questioned the currency of the concept of cyborg by offering a historical approach that started with the advent of postmodernity and ended with the latest hightech blockbuster, Avatar (2009). The idea of creating something new through a productive repetition and transformation was linked to the concept of cyborg since it was coined. Thus, actualised cyborgs flood our screens today as both a strategy to rework, to embed the concept in our actuality and to emphasise the hypermediacy and immediacy of new media. Westermann's contextualisation of the term cyborg in the digital era extends the work of Lev Manovich on visual excess associated with new media, when he discusses "the Illusions" and "Socialist Realism" (185-89). Veronique Sina's paper dealt with the gender issues of heroes and mixedcreatures that inhabit comics and comic-based movies. Through a juxtaposition of mainstream and underground transgender adventurers, she highlighted the constraints of the media industry and popular culture based solely on revenues when it comes to handling transgression of binary understandings of gender, as has been stated by Judith Butler (Osborne) and bell hooks (18-21) among others. Uwe Wippich presented the final paper of the panel, which was a fresh and highly entertaining account of the reproductions of Nefertiti. This ancient bust has been the subject of numerous investigations. In the 1920s Nefertiti was the equivalent of a cover girl and a trendsetter: streets were filled with her makeup style. In 2003 a body was given to the bust by artists András Gálik and Bálint Havas, which provoked protests and indignation. The manipulation of the bust due to this project and its various relocations within Berlin has been closely monitored, offering a mediated and remediated representation of the figure once signalled by the press as the city's most beautiful citizen. Wippich's account of the shifting fortunes of the Nefertiti bust demonstrated that theoretical concepts traditionally associated with screens - remediation and transmedia by Henry Jenkins - are equally productive when applied to other visual media such as sculpture.

I also attended the two dedicated photography panel sessions: "Pictures at Upheaval: Photography and Digital Culture" and "Accidents, Diffusions and Interferences: Creative Mischances in Amateur Photography". Both panels were the result of a year's collaborative labour by the GfM Photography Working Group. However, while photography was the medium of discussion, the topics were of interest to a variety of disciplines as they covered a wide range of issues: materiality; the index and its apparent dissolution; digital circulation of images; labels; metadata; folksonomy; recontextualisation of private visual material; contexts of image production and recollection; theories of affect in regard to visual material; and the question of oblivion and memory. In both cases, the presentations stimulated a lively discussion. Several methodological issues were raised regarding work with digital photography, including social networking. More specifically, a case study of Flickr by Susanne Holschbach addressed the dynamics of social networking and the quick and widespread distribution of digital photographs as current challenges to photographic discourse. The second case study of the panel, by Winfried Gerling, featured Google Earth and discussed the relevance of metadata, particularly its questionable indexical character, and subsequently new processes of legitimating the (digital) photographic image. Metadata seem to bridge the gap produced by digital photography to 
Bazin's ontology of the photographic image (4-9). Just as realism is inherent to the photographic/filmic analogue image, metadata are intrinsic to digital material. The contribution of Marc Giess connected the concept of the photographic portrait with Flickr, linking the debate around a media philosophy-orientated discussion, namely the debate between realistic and nominalistic approaches. The massive and continuous uploading and exchange of photographs in social networks was signalled as a way to "nicht-vergessen", or "not-forget", the past and to challenge general views and stereotypical approaches. The commonality experienced in social networking acts as a substitute for the assumptions and over-simplified generalities concerning "otherness". In this manner Giess addressed a segment of the audience that might have otherwise felt alienated by the more photography-orientated speeches. In the second panel, Kerstin Brandes presented her revision of the question of photographic evidence by using the website $<$ http://www.volks-bild.com/>, and by happy coincidence researcher and author of this artistic web-project were brought together in the same room. The fact that Susanne Wehr was part of the audience fostered a highly productive exchange of perspectives and discussion around reappropriation and recontextualisation of amateur images by both cultural industries and the art market.

\section{Evaluation}

The GfM used the term "dysfunctionality" to call for a productive debate around the popular assumption that only outmoded, out-of-order media processes are open for discussion. The notion of interference was also included under dysfunction, as well as practices and devices or mechanisms that generate interferences. During the four days of the conference, keynotes and panels handled the concept of dysfunctionality from a variety of perspectives. Often a specific case study (e.g. experimental films by women) illustrated the productivity of the term "dysfunctionality" within Media Studies discourse. Sometimes the synergy of an interdisciplinary approach was highlighted (e.g. "Media Culture and Education: Dysfunctionality Digital Native").

The general goal of improving an understanding of various media forms and how they function, by working within the wide spectrum of meanings located within the concept of dysfunctionality, was effectively achieved. After four days of intense debate around interferences, errors, assumptions, subversion and more, no general consensus about the term was reached, but this was not necessarily the aim of the conference. Instead, a plurality of productive approaches to dysfunctionality enabled a revision of the current state of affairs in German Media Studies. I am already eager to see what happens next year, when researchers will be inspired by the 2012 conference title, "Speculation". Hosting the event in Frankfurt, Germany's economic and banking centre, would seem to fit with traditional understandings of the concept, and these will surely be challenged next October by panellists and other academic participants alike. 


\section{Works Cited}

Avatar. Dir. James Cameron. $20^{\text {th }}$ Century Fox, 2009. DVD.

Bazin, André. “The Ontology of the Photographic Image." Trans. Hugh Gray. Film Quarterly 13.4 (1960): 4-9. Print.

"Fachgeschichte: Entwicklung der Medienwissenschaft". GfM-Gesellschaft Fuer Medienwissenschaft. n.d. Web. 16 Feb. 2012.

$<$ http://www.gfmedienwissenschaft.de/gfm/gfm/fachgeschichte_entwicklung_der_medie nwissenschaft.html>

"Die Gesellschaft fuer Medienwissenschaft". GfM-Gesellschaft Fuer Medienwissenschaft. n.d. Web. 16 Feb. 2012.

$<$ http://www.gfmedienwissenschaft.de/gfm/gfm/die_gesellschaft_fuer_medienwissensch aft.htm $>$

"GfM-Jahrestagung 2011 in Potsdam thematisiert "Dysfunktionalitaeten". $r: k: m-$ rezensionen:kommunikation:medien. Institut fuer Journalistik, Technische Universitaet Dortmund. 19 July 2011. Web. 24 Feb. 2012. <http://www.rkmjournal.de/archives/6269>

Hooks, Bell. "Cultural Criticism and Transformation.” Mediaed.org. Media Education Foundation, 24 Jan. 2005. Web. 20 Mar. 2012.

“Jahrestagung 2011: Dysfunktionalitaeten". GfM-Gesellschaft Fuer Medienwissenschaft. 19 July 2011. Web. 16 Feb. 2012.

$<$ http://www.gfmedienwissenschaft.de/gfm/gfm/index.php?TID=742>

Jenkins, Henry. Convergence Culture: Where Old and New Media Collide. New York: NYU Press, 2006. Print.

Manovich, Lev. “The Language of New Media.” Manovich.net. 12 July 2000. Web. 20 Mar. 2012.

Osborne, Peter, and Segal, Lynne. "Extracts from Gender as Performance: An Interview with Judith Butler." www.theory.org.uk Resources: Judith Butler interview. Theory.org.uk. Web. 20 Mar. 2012.

Patricia Prieto Blanco is a videoartist, photographer and media researcher. After graduating in Audiovisual Communication in Madrid, she moved to Germany to complete her Masters in Media Studies at the Ruhr University. Since September 2011 she is based at the Huston School of Film and Digital Media (National University of Ireland, Galway) researching re- 
configurations in social uses of digital photography through the conceptual lens of familial intimacy. Her theoretical work has been published in Networking Knowledge, the Postgraduate Journal of MeCCSA, and will soon be part of a German volume on Performanz/Performance. Her practice-based research travelled in 2011 to Kobe for the Cultural Typhoon and to Bradford for the Documenting Fictions Congress. She is currently working on a project with American photographer Jacob Lange on digital photographic archives at Belfast-Exposed; and on a videoart about the body-mechanics of playing with German-based artist Volker Dietze. For more information: osdiasda.deviantart.com. 